\title{
Distribution and effects of the muscarinic receptor subtypes in the primary visual cortex
}

\author{
Marianne Groleau, Jun II Kang, Frédéric Huppé-Gourgues and Elvire Vaucher* \\ Laboratoire de Neurobiologie de la Cognition Visuelle, École d'Optométrie, Université de Montréal, Montréal, QC, Canada
}

Muscarinic cholinergic receptors modulate the activity and plasticity of the visual cortex. Muscarinic receptors are divided into five subtypes that are not homogeneously distributed throughout the cortical layers and cells types. This distribution results in complex action of the muscarinic receptors in the integration of visual stimuli. Selective activation of the different subtypes can either strengthen or weaken cortical connectivity (e.g., thalamocortical vs. corticocortical), i.e., it can influence the processing of certain stimuli over others. Moreover, muscarinic receptors differentially modulate some functional properties of neurons during experience-dependent activity and cognitive processes and they contribute to the fine-tuning of visual processing. These functions are involved in the mechanisms of attention, maturation and learning in the visual cortex. This minireview describes the anatomo-functional aspects of muscarinic modulation of

Edited by:

Sukumar Vijayaraghavan, University of Colorado Health

Science Center, USA

Reviewed by:

Ricardo C. Araneda,

University of Maryland, USA Rory McQuiston,

Virginia Commonwealth University,

USA

${ }^{*}$ Correspondence: Elvire Vaucher, Laboratoire de Neurobiologie de la Cognition Visuelle, École d'optométrie, Université de Montréal, CP 6128, succ. Centre-ville,

Montréal, QC H3C 3J7, Canada elvire.vaucher@umontreal.ca

Received: 15 April 2015 Accepted: 04 June 2015 Published: 19 June 2015

Citation:

Groleau M, Kang Jl, Huppé-Gourgues $F$ and Vaucher $E$ (2015) Distribution and effects of the muscarinic receptor subtypes in the primary visual cortex.

Front. Synaptic Neurosci. 7:10. doi: 10.3389/fnsyn.2015.00010 the primary visual cortex's (V1) microcircuitry.

Keywords: acetylcholine, attention, basal forebrain, cholinergic system, GABAergic interneurons, muscarinic transmission, visual cortex, visual learning

\section{Introduction}

Acetylcholine (ACh) is released in the primary visual cortex (V1) by visual stimulation, especially by novel stimuli (Collier and Mitchell, 1966; Laplante et al., 2005) and attentional demand (Herrero et al., 2008). The cholinergic innervation of the cortex originates from the basal forebrain neurons through topographical projections. Specifically, V1 receives cholinergic projections from the horizontal limb of the diagonal band of Broca (Gaykema et al., 1990; Laplante et al., 2005). In V1, ACh modulates the responses of cortical neurons to visual or cortico-cortical inputs through two receptor families, the metabotropic muscarinic receptors (mAChRs) and the ionotropic nicotinic receptors (nAChRs; Prusky et al., 1987; Volpicelli and Levey, 2004; Disney et al., 2007; Thiele, 2013). These receptors are located on axons originating from thalamic, cortical or basalocortical fibers as well as on pyramidal excitatory neurons and inhibitory GABAergic interneurons (Zilles et al., 1989; Mrzljak et al., 1993; Hashimoto et al., 1994; Thiele, 2013). They are found in each level of the V1 cortical circuitry, i.e., the recipient layer of the thalamic projections, in layer IV neurons and their lateral projections, and throughout the vertical intracortical connections that convey the information to supragranular (I, II/III) and infragranular (V, VI) layers (Burkhalter, 1989; Van Hooser, 2007).

Abbreviations: ACh, acetylcholine; GABA, $\gamma$-Aminobutyric acid; KO, knock-out; mAChRs, muscarinic acetylcholine receptors; M1, M2, M3, M4, M5, muscarinic receptor subtypes 1-5; nAChRs, nicotinic acetylcholine receptors; NMDAR, N-Methyl-D-aspartate receptor; V1, primary visual cortex. 
The V1 microcircuitry, whose connectivity is organized vertically and horizontally, provides an anatomical substrate for the receptive field-binocularity (Dräger and Olsen, 1980; Grieve, 2005) or ocular dominance (LeVay et al., 1978; Cynader et al., 1987) - and for the selective properties of the neurons-orientation (Grinvald et al., 1986), direction (Shmuel and Grinvald, 1996; DeAngelis et al., 1999) and contrast preference (Levitt and Lund, 1997), for example. Each functional property of the neuron results from the sum and diversity of the connections it receives and might be adapted according to the strength of the inputs received. The strength of the neuronal response further determines the transmission and processing of the stimulus in higher cognitive cortical areas. V1 is thus the first cortical step of the integration of complex visual stimuli. Its modulation by ACh is then important for the selection of specific stimuli from the visual field and the elaboration of fine visual conscious perception.

In this mini review, we discuss how muscarinic transmission plays a key role in neuronal transmission, synaptic strength and the interaction between excitatory and inhibitory neurons. These mechanisms lead to the reinforcement of particular neuronal connections and contribute to the processes of memory, perceptual learning and attention but also to the maturation and the fine-tuning of the visual cortex.

\section{Muscarinic Receptors' Organization in the Primary Visual Cortex}

In the neonatal and adult cortices, the five subtypes of mAChRs (M1-M5) are present in both pre- and postsynaptic positions (Wess, 2003; Krnjević, 2004). The terms pre- and postsynaptic are used here to identify the neuronal location of the receptors even though the cholinergic system acts in the cerebral cortex mostly by diffuse transmission rather than synaptic transmission (Umbriaco et al., 1994; Descarries et al., 1997) except in layer V, where the synaptic density on cholinergic terminals is particularly rich (Avendano et al., 1996; Turrini et al., 2001). Depending on the species, the density of each subtype of mAChR differs across the cortical layers (I-VI; Gu, 2003). The species-selective immunocytochemical detection of the different subtypes of mAChRs may, however, vary due to the poor specificity of the antibodies, especially in rodents (Jositsch et al., 2009). Many studies have thus used binding or mRNA expression of the mAChRs to localize them within the cortical microcircuitry. In the rodent's visual cortex, the subtypes M1 and M2 predominate. In humans (and primates), the subtypes M1, M2 and M4 prevail (Flynn et al., 1995).

The M1, M3 and M5 subtypes are mainly post-synaptic and lead to an increase in the intracellular $\mathrm{Ca}^{2+}$ concentration by activating phospholipase C (PLC; Figure 1A). These receptors are coupled with $\mathrm{G} \alpha \mathrm{q} / 11 \mathrm{G}$-proteins. In the cerebral cortex, the M1 subtype, the main excitatory mAChR subtype (Levey et al., 1991; Caulfield and Birdsall, 1998; Lucas-Meunier et al., 2003; Wess, 2003; Krnjević, 2004; Thiele, 2013), appears to be present mainly in layers II/III and VI, but it is found in all the cortical layers (Levey et al., 1991; Aubert et al., 1996; Vaucher

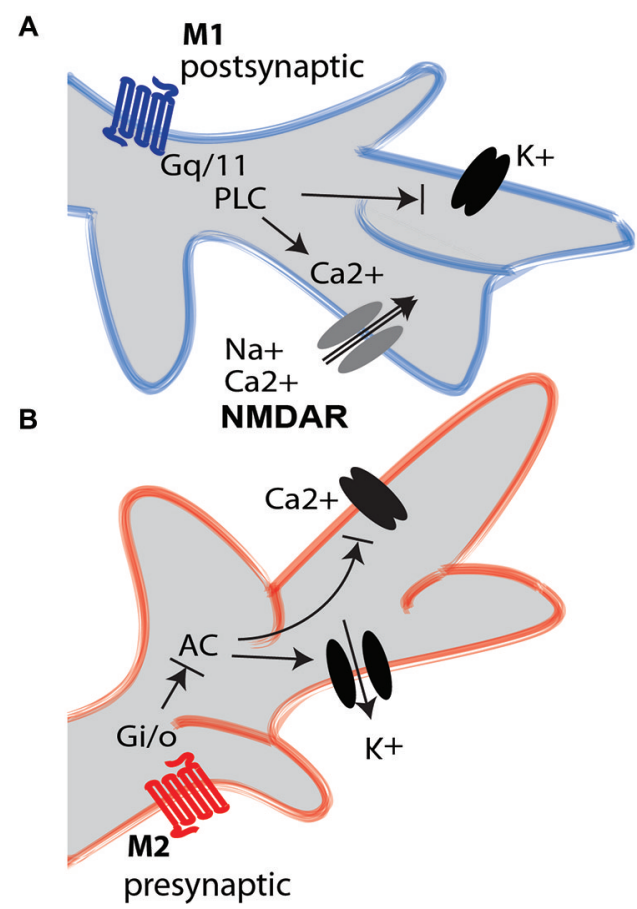

FIGURE 1 | M1 and M2 mAChRs intracellular mediation. (A) The activation of the $M 1$ excitatory $m A C h R$ (blue) triggers the $G_{q / 11}$ G-protein, which activates phospholipase $\mathrm{C}$ (PLC). This induces depolarization of the neuronal element by closing different $\mathrm{K}^{+}$channels, including voltage-gated channels and leaky channels, and by activating calcium channels that increase the intracellular concentration of $\mathrm{Ca}^{2+}$ from the intracellular stores. The M1 receptor induces long-term potentiation-like effects in glutamatergic neurons through interaction with NMDA receptors (NMDARs). The M1 receptors are mainly postsynaptic, although they are also found on some glutamatergic axon terminals. (B) The activation of the M2 inhibitory mAChR (red) triggers the $\mathrm{G}_{\mathrm{i} / \mathrm{o}} \mathrm{G}$-coupled protein, which inhibits adenylate cyclase (AC). This closes the $\mathrm{Ca}^{2+}$ voltage-gated channel and opens the $\mathrm{K}^{+}$channel to hyperpolarize the neuron. The $\mathrm{M} 2$ receptors are mainly presynaptic, although they are also found on some GABAergic interneurons.

et al., 2002; Roberts et al., 2005). In rats, M1 mAChRs represent almost $40 \%$ of the total mAChRs (Levey et al., 1991), and in the human occipital cortex, they represent nearly 35\% (Flynn et al., 1995). This subtype is found essentially on the cell bodies and dendrites of postsynaptic pyramidal cells (Mrzljak et al., 1993; Gu, 2003; Gulledge et al., 2009; Figure 2A). However, in the primate's visual cortex, the M1 mAChR seems to be largely expressed on GABAergic interneurons (Disney et al., 2006). M1 is also found on the cortico-cortical fibers, where it plays an inhibitory role by reducing excitatory transmission across horizontal as well as long-range cortico-cortical connections (Amar et al., 2010). The M3 subtype is located on the rat intracortical cell bodies and dendrites at a postsynaptic level, but it is virtually not detected in V1 by immunocytochemistry (Levey et al., 1994). In spite of this, the M3 receptor appears to be involved in several functions of the rodent's V1 (see other sections), and it is expressed in GABAergic interneurons, where it enhances the transmission of $\gamma$-Aminobutyric acid (GABA; Amar et al., 2010). The M5 subtype is found on endothelial cells and only small number is found in the rodent's 
A

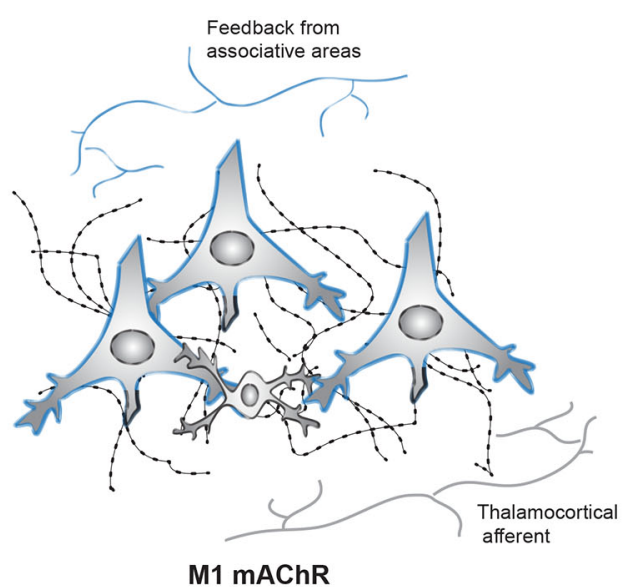

Main excitatory mAChR subtype (Levey and al., 1991; Caulfield and Birdsall, 1998; Lucas-Meunier et al., 2003; Wess, 2003; Krnjevic, 2004; Thiele, 2013)

Present in all cortical layers (Levey et al., 1991; Aubert et al., 1996)

Present on cell bodies and dendrites of pyramidal cells (Mrzljak et al., 1993; Gu, 2003; Disney and Aoki, 2008; Gulledge et al., 2009)

Present on corticocortical fibres (Gil et al., 1997; Amar et al., 2010) Increases the neuronal optimal spatial frequency (Groleau et al., 2014) Enhances glutamatergic drive except in the layer $\mathrm{V}$ (Gulledge et al., 2009; Amar et al., 2010)

Influences contrast sensitivity (Groleau et al., 2014; Bhattacharyya et al., 2012)

Involved in the plasticity of the developing visual cortex

(Gu and Singer, 1993; Kirkwood et al., 1995)

Involved in long-term potentiation and long-term depression

(Greuel et al., 1988; Kirkwood et al., 1995, 1999; Gu, 2003; Origlia et al., 2006)
B

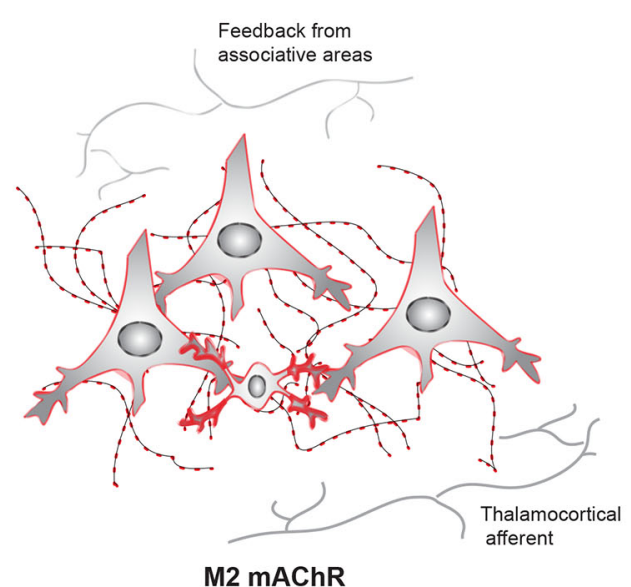

M2 mAChR

Cholinergic inhibitory autoreceptor - decreases ACh release
(Mrzljak et al., 1993)
Present in layers IV and V (Zilles et al., 1989)
Present on cell bodies and terminals of GABAergic neurons
(Salgado et al., 2007)
Present on basalocortical fibres (Mrzljak et al., 1993)
Fine tunes neuronal connectivity (Groleau et al., 2014)
Modulates the incortical GABAergic inhibitory drive
(Salgado et al., 2007)
Increases cortical sensitivity (Sarter et al., 2005; Salgado et al., 2007)
Involved in the plasticity of the developing visual cortex
(Gu and Singer, 1993)
Involved in long-term potentiation (Origlia et al., 2006)

\section{non selective mAChRs modulation}

Modulates neuron selective properties (orientation, direction, receptive field) (see text for references)

Facilitates or suppresses intracortical neurons response (Gil et al., 1997)

Suppresses the horizontal spread of excitation in V1 (Kimura et al., 1999) by inhibiting lateral connections

Contributes to attentional mechanisms (Herrero et al., 2008; Klinkenberg and Blokland, 2010)

Influences gamma band activity (Rodriguez et al., 2004; Bartos et al., 2007; Sohal et al., 2009)

Improves visual perception (Kang et al., 2014)

Increases GABAergic neuron activity following basal forebrain stimulation (Dotigny et al, 2008; Alitto and Dan, 2012)

FIGURE 2 | Distribution of the mAChRs on the inhibitory and excitatory cells of the cortical microcircuitry and their associated functions. Integration of the information within $\mathrm{V} 1$ is mediated through the vertical and horizontal connections between excitatory neurons (large cells) and inhibitory interneurons (small cells). The cortical connections originating from associative areas are represented on the top, and the thalamocortical afferents are represented on the bottom. The cholinergic fibers and their varicosities (swellings) are represented on the back. (A) The M1 receptor (blue) is present on the cell bodies and dendrites of pyramidal cells in V1 as well as on the long range cortical connections from associative areas. (B) The M2 mAChR (red) is present on the inhibitory interneurons in $\mathrm{V} 1$ and also on cholinergic fibers and some pyramidal cells. The thicker the colored line is, the higher the expression of the receptor is. Principal functions of these specific receptors or of the sum of all mAChRs - demonstrated by non-selective agonists or antagonists - are represented in the left (M1 mAChR, blue), right (M2 mAChR, red) and bottom (undifferentiated action of $\mathrm{mAChRs}$ ) lines.
(Elhusseiny and Hamel, 2000) and human's visual cortex (Flynn et al., 1995). The M5 subtype has a major function in cortical perfusion.

The M2 and M4 subtypes are found mostly at the presynaptic level, extending the opening of potassium channels by reducing the intracellular concentration of cAMP (Figure 1B). They are coupled to $\mathrm{G} \alpha_{\mathrm{i} / \mathrm{o}} \mathrm{G}$-protein, inhibiting adenylyl cyclase (Caulfield and Birdsall, 1998; Wess, 2003). These subtypes appear to have an inhibitory function. Among the presynaptic receptors in the rodent and human visual cortex, the M2 receptor is very abundant and the M4 subtype is less prevalent (Flynn et al., 1995; Zhang et al., 2002). The M2 subtype is mainly found in layer IV (thalamic recipient) and layer V in the rat's V1 (Zilles et al., 1989), but its distribution in the cortical layers, however, varies depending on the species (Gu, 2003). Its expression is up to $36 \%$ of the total mAChRs in the primate's V1 (Flynn et al., 1995). At the cholinergic terminals, the M2 subtype is the main inhibitory autoreceptor (Mrzljak et al., 1993; Figure 2B) and it decreases the release of ACh, thereby controlling extracellular levels of ACh by negative feedback (Rouse et al., 1999; Douglas et al., 2001; Bymaster et al., 2003). On GABAergic terminals, M2 activation inhibits the 
release of GABA (Salgado et al., 2007). Although predominantly presynaptic, M2 and M4 receptors are also present on the cell bodies of GABAergic interneurons in layers II/III and IV (Volpicelli and Levey, 2004)-representing 29\% of the GABAergic cells in the primate (Disney and Aoki, 2008) - and on pyramidal cells (Mash and Potter, 1986; Kimura and Baughman, 1997), where its activation inhibits excitatory conductance (Amar et al., 2010).

\section{Muscarinic Influence on Visual Processing in V1}

The action of ACh on both pre- and postsynaptic mAChRs results in improved sensory coding of novel and trained visual stimuli (Kang et al., 2014). This change in neuron properties is due to improved neuronal sensitivity resulting from a change in membrane conductance, synaptic strength or connectivity with adjacent neurons and long-range cortical projections. The M1 and M3 subunits seem to have a strong influence on neuronal sensitivity because the optimal spatial frequency of the neuronal population is decreased and the contrast sensitivity is increased in M1/M3-KO mice (Groleau et al., 2014).

$\mathrm{ACh}$ has been shown to influence the response of V1 neurons in terms of intensity (Bröcher et al., 1992; Lewandowski et al., 1993; Gil et al., 1997; Kimura et al., 1999; Kirkwood et al., 1999; Kuczewski et al., 2005; Levy et al., 2006; Thiel, 2007; Dotigny et al., 2008; Kang and Vaucher, 2009; Pinto et al., 2013; Soma et al., 2013a,b,c), preferred responses (Murphy and Sillito, 1991; Roberts et al., 2005; Thiel, 2007) and receptive field properties (Herrero et al., 2008; Thiel and Fink, 2008). $\mathrm{ACh}$ executes an action by controlling the gain of the neuron response (Soma et al., 2012, 2013a). For example, ACh increases the gain of the visual response to contrast (Bhattacharyya et al., 2013; Soma et al., 2013a) or orientation selectivity (Zinke et al., 2006). These effects might be due to the facilitation of the depolarization of glutamatergic neurons in response to visual input (Figures 1, 2) due to the increased concentration of $\mathrm{Ca}^{2+}$ associated with NMDA receptor-gated conductance (Kirkwood et al., 1999) or the reduction of membrane K+ conductance (Thiele, 2013), both potentiated by the muscarinic receptors. The M1 mAChR also amplifies the spiny stellate cell/pyramidal cell response through a postsynaptic intracellular pathway (Gu, 2003), but inhibition through the M4 mAChR has also been observed on spiny neurons in the somatosensory cortex (Eggermann and Feldmeyer, 2009). M2 receptor activation of GABAergic perisomatic terminals (Figures 1, 2) inhibits the release of GABA, causing an increase in the cortical sensitivity of glutamatergic neurons (Sarter and Parikh, 2005; Sarter et al., 2005; Salgado et al., 2007). The M2 subtype, which is largely found on GABAergic cells in rodents, plays a strong role in the modulation of the intracortical GABAergic inhibitory drive.

The amplification of the neuronal response to a certain stimulus could also be due to the depression of the neural response of adjacent neurons that have distinct receptive field and selective properties. By acting on horizontal connections, ACh might thereby modulate the weight of a selective stimulus. In humans, an increase in extracellular ACh levels following the administration of donepezil (an inhibitor of the cholinesterase inhibitor) reduces the horizontal spread of the excitatory response following visual stimulation. This could result from a reduction in the size of the excitatory receptive field by $\mathrm{ACh}$ due to the depression of the lateral connectivity (Silver et al., 2008). The reduction of the spread of lateral excitation (Kimura et al., 1999) and neuron depression (Kimura and Baughman, 1997; Soma et al., 2013b) following ACh administration is also shown in rodents. It is, however, possible that the cholinergic system not only inhibits the lateral competition but also strengthens the connectivity for a trained orientation, thereby increasing the number of responding neurons to this trained orientation (Kang et al., 2014). In primates, it has been suggested that the lateral connections between similarly tuned neurons are reinforced by cholinergic stimulation (Ramalingam et al., 2013). Such a change increases the cortical response (Frenkel et al., 2006), enhances the sensitivity of trained visual stimulus (Matthews et al., 1999) and thus facilitates the discrimination from the background (Jehee et al., 2012).

An alternate action of the mAChRs in the increase of the neuron sensitivity of the afferent visual inputs is the increase in the long-term responsiveness of the neuron, leading to an acquired change of its functional property. The action mechanism of ACh strongly resembles long-term potentiation (Gu, 2003; Kang and Vaucher, 2009; Rodriguez et al., 2010; Kang et al., 2014) and heterosynaptic facilitation. When repetitive visual stimulation of sub-optimal orientation is paired with the application of $\mathrm{ACh}$, the responses of neurons become stronger and more long-lasting at the expense of a diminishing response to the previous optimal orientation (Greuel et al., 1988; Kang et al., 2014). Moreover, coupling visual stimulation with cholinergic stimulation induces long-lasting increases in cortical responsiveness and improved visual acuity (Dringenberg et al., 2007; Kang and Vaucher, 2009; Kang et al., 2014) relative to NMDA-dependent mechanisms. The joint action of ACh on both GABAergic and glutamatergic neurons also compromises the excitation-inhibition balance (Amar et al., 2010). This would induce cortical plasticity (Arckens et al., 2000; Hensch and Fagiolini, 2005; Benali et al., 2008; Mainardi et al., 2009; Sale et al., 2010).

\section{Muscarinic Influence on the Development and Maturation of the Visual Cortex}

The above muscarinic contribution to the tuning of the receptive field and preferred properties of V1 neurons has a potent role in the maturation and fine-tuning of the visual cortex. The retinotopic organization of V1 is established during embryogenesis, and the properties of the neurons are acquired and refined during the post-natal period with visual experience, especially during the critical period. The critical period is thus an important time in the formation of synapses and pruning (Consonni et al., 2009) and for synaptic plasticity, which strengthens and stabilizes the neural connections. 
It has been shown that the cholinergic system is essential during embryogenesis, although the amount of M1, M2 and M3 receptors is very small at the end of the rat prenatal period compared with the adult animal. The cholinergic innervation in V1 is settled at the end of the first postnatal week, and a robust cholinergic staining is visible at P8 (Mechawar and Descarries, 2001). It is similar to the adult cholinergic innervation of the cortex at the end of the second postnatal week (Mechawar and Descarries, 2001). The cholinergic receptors are present in the cortex before the beginning of the critical period, which starts at the end of the third postnatal week (Fagiolini et al., 1994). Between weeks 3 and 5, M1 and M3 levels reach the levels found in the mature animal, while it is not until week 5 that the M2 receptor level reaches that found in the adult (Aubert et al., 1996). Thus, the level of muscarinic expression fits well with the acquisition of the functional properties of the V1 neurons and the establishment of the functional maps. In agreement with a role of the mAChRs in the maturation of the visual cortex rather than development by itself, we recently showed that the gross retinotopic map was virtually unaffected by diverse mAChR subtypes' deletion (Groleau et al., 2014). However, there was altered neuronal connectivity in adult M2/M4-KO mice as visualized using intrinsic signal optical imaging. In these animals, the spatial representation of the visual field was not smooth as it was in control mice, but rather it was stepwise, suggesting a lack of finetuning of the retinotopic map. M1/M3 deletion resulted in an alteration of the neurons' sensitivity. Therefore, different $\mathrm{mAChRs}$ or combinations thereof can modulate visual properties during the establishment of visual functions (Groleau et al., 2014).

In rodents, a basal forebrain lesion during the critical period transiently affects the ocular dominance of the visual cortical neurons, i.e., the preference response of the neuron to input of one eye over the other. In basal forebrain lesioned animals, an altered ocular dominance toward the contralateral eye is observed. However, at the end of the critical period, a cholinergic deafferentation does not alter ocular dominance (Siciliano et al., 1997). Immunolesion of the cholinergic fibers affects the mRNA expression of the M1 and M2 mAChR subtypes as measured by RT-PCR in young animals (Kuczewski et al., 2005), suggesting the involvement of these mAChR subtypes in the plasticity of the developing visual cortex. At the receptor level, the M1 subtype, but not the M2 subtype, is involved in ocular dominance because its blockade prevents the shift of ocular dominance ( $\mathrm{Gu}$ and Singer, 1993).

The stabilization of the neuronal connections during maturation happens through synaptic plasticity, i.e., longterm potentiation and long-term depression. In the cortex, long-term potentiation is strongly active during the critical period and experience-dependent plasticity (Crair and Malenka, 1995; Kirkwood et al., 1995). The involvement of mAChRs in critical period plasticity has been demonstrated through in vitro electrical stimulation. Long-term depression is dependent on the M1 receptor in layers II/III of the V1 in young rats (3-4 weeks). In adults, long-term depression also depends on the M3 receptor in addition to the M1 subtype (McCoy and McMahon, 2010). When the visual cortex was stimulated through a $100 \mathrm{~Hz}$ tetanic stimulation, long-term potentiation was recorded in the cortex of young M1/M3-KO, but not in $\mathrm{M} 2 / \mathrm{M} 4-\mathrm{KO}$, mice. Conversely, low frequency stimulation produced expected long-term depression in $\mathrm{M} 2 / \mathrm{M} 4-\mathrm{KO}$ mice while long-term potentiation was recorded in $\mathrm{M} 1 / \mathrm{M} 3-\mathrm{KO}$ mice. Thus, it appears that various subtypes of $\mathrm{mAChRs}$ regulate distinct forms of long-term synaptic plasticity (Origlia et al., 2006).

\section{Muscarinic Influence on Visual Cognition}

In adults, the effect of $\mathrm{ACh}$ on neuron sensitivity and the long-lasting enhancement of neuronal responses contribute to the processes of attention and perceptual learning. Indeed, the intensity of the response of $\mathrm{V} 1$ cells to a particular stimulus as well as the number of cells responding to the stimulus determine the weight for further processing of this stimulus in higher-level cortical areas, i.e., enhanced or depressed visual processing. In learning and experiencedependent acquisition of new visual abilities, the response selectivities of V1 neurons are changed (Froemke et al., 2007), as are neural connections, with an increased number of synaptic contacts or the formation of new neurons (Majewska and Sur, 2003; Hofer et al., 2009; Yamahachi et al., 2009). The synapse strength of V1 neurons is adjusted by longterm potentiation or depression, which is dependent on $\mathrm{N}$ Methyl-D-aspartate receptor (NMDAR; Quinlan et al., 2004; de Marchena et al., 2008; Kang and Vaucher, 2009) and induces a persistent increase of cortical responsiveness to a particular stimulus. The synchronization of a large number of neurons firing rises to macroscopic oscillations, which change cortical activity.

Oscillation in gamma frequency is suggested to reflect cognitive activity, such as sensory perception (Cardin et al., 2009), attention (Fries, 2009) and learning (Paik and Glaser, 2010; Headley and Weinberger, 2011). Previous studies have demonstrated that cholinergic stimulation could increase gamma band activity (Rodriguez et al., 2004), and this can enhance visual encoding (Goard and Dan, 2009) or contrast sensitivity (Bhattacharyya et al., 2013). Specifically, the muscarinic influence on gamma band activity might be due to its action on GABAergic cells, which are also involved in gamma oscillations (Bartos et al., 2007; Sohal et al., 2009).

A number of studies have shown that lesion or blockade of the cholinergic system with antagonist injection in the primary sensory cortex could significantly reduce attentional task performance (Klinkenberg and Blokland, 2010). Different studies have shown that ACh could increase either pre- or postsynaptic responses via mAChR (Gil et al., 1997; Oldford and CastroAlamancos, 2003). Such variation enables the cholinergic system to amplify relevant information at the expense of unreliable information, which is consistent with the function of attention (Briggs et al., 2013). A voluntary focus on a stimulus observed in top down attention originates from long range cortico-cortical connections from associative areas and the prefrontal cortex compared with bottom up attention reaching layer IV from 
thalamic afferents. Bottom up attention does not seem to be altered by the cholinergic system (Rokem and Silver, 2010), but sustained attention is altered by it. For example, cholinergicdependent visual attention also results in modulating the size of the cortical receptive field. Focused attention within the receptive field will result in a decrease of its size, whereas attention paid right next to the receptive field will result in an increase in its size (Anton-Erxleben et al., 2009). Scopolamine, a non-specific mAChR antagonist, has been shown to disrupt the attentional mechanism at various levels (Klinkenberg and Blokland, 2010). Similarly, in V1, voluntary visual attention is suppressed by the blockade of mAChR (Herrero et al., 2008).

Compared with attention, which emphasizes the upcoming information, perceptual learning is a long-term process that improves behavioral performance after repetitive training. Recent studies have demonstrated that cholinergic innervation in V1 facilitates perceptual learning in rodents (Kang et al., 2014) and in humans (Rokem and Silver, 2010). Cholinergic activation during a visual task seems to increase the cortical response, resulting in an enhancement of visual capacity. An increase in the cortical response to the trained stimulus suggests an increase in the number of neurons encoding stimulus properties (Frenkel et al., 2006) and the efficiency of the neuronal transmission between neurons (Gilbert and Li, 2012). mAChRinduced long-term modulation could thus change the efficiency of selective neuronal networks for this trained stimulus through the modulation of lateral connectivity and the enhancement of some feed-forward inputs. For example, a visual stimulus

\section{References}

Amar, M., Lucas-Meunier, E., Baux, G., and Fossier, P. (2010). Blockade of different muscarinic receptor subtypes changes the equilibrium between excitation and inhibition in rat visual cortex. Neuroscience 169, 1610-1620. doi: 10.1016/j.neuroscience.2010.06.019

Anton-Erxleben, K., Stephan, V. M., and Treue, S. (2009). Attention reshapes center-surround receptive field structure in macaque cortical area MT. Cereb. Cortex 19, 2466-2478. doi: 10.1093/cercor/bhp002

Arckens, L., Schweigart, G., Qu, Y., Wouters, G., Pow, D. V., Vandesande, F., et al. (2000). Cooperative changes in GABA, glutamate and activity levels: the missing link in cortical plasticity. Eur. J. Neurosci. 12, 4222-4232. doi: 10.1046/j. 0953-816x.2000.01328.x

Aubert, I., Cécyre, D., Gauthier, S., and Quirion, R. (1996). Comparative ontogenic profile of cholinergic markers, including nicotinic and muscarinic receptors, in the rat brain. J. Comp. Neurol. 369, 31-55. doi: 10.1002/(sici)10969861(19960520)369:1<31::aid-cne3>3.0.co;2-1

Avendano, C., Umbriaco, D., Dykes, R. W., and Descarries, L. (1996). Acetylcholine innervation of sensory and motor neocortical areas in adult cat: a choline acetyltransferase immunohistochemical study. J. Chem. Neuroanat. 11, 113-130. doi: 10.1016/0891-0618(96)00132-9

Bartos, M., Vida, I., and Jonas, P. (2007). Synaptic mechanisms of synchronized gamma oscillations in inhibitory interneuron networks. Nat. Rev. Neurosci. 8, 45-56. doi: 10.1038/nrn2044

Benali, A., Weiler, E., Benali, Y., Dinse, H. R., and Eysel, U. T. (2008). Excitation and inhibition jointly regulate cortical reorganization in adult rats. J. Neurosci. 28, 12284-12293. doi: 10.1523/jneurosci.195208.2008

Bhattacharyya, A., Veit, J., Kretz, R., Bondar, I., and Rainer, G. (2013). Basal forebrain activation controls contrast sensitivity in primary visual cortex. $B M C$ Neurosci. 14:55. doi: 10.1186/1471-2202-14-55 with the preferred orientation presented outside of the classic receptive field normally suppresses the neuronal visual response. However, after a perceptual learning task, the neuronal response can be enhanced (Kapadia et al., 2000) by this stimulus. Overall, a long-term increase in cortical neurons' activation could be due to $\mathrm{mAChR}$ strengthening the lateral connectivity between similarly tuned neurons, thereby changing the orientation index or the receptive field size.

\section{Conclusion}

Muscarinic transmission influences visual processing by facilitating or depressing neuronal responses to specific stimuli and by modulating lateral connections' strength and neuronal synchronization. This effect is primarily mediated through M1 and M2 mAChRs, the predominant muscarinic subtypes in $\mathrm{V} 1$, at least in rodents. These effects result in fine-tuning of the neuronal and network properties during maturation, attention and perceptual learning.

\section{Acknowledgments}

The authors acknowledge the financial support of the Canadian Institutes of Health Research (CIHR, MOP-111003) and the Natural Sciences and Engineering Research Council of Canada (NSERC, 238835-2011). MG and JIK received financial support from the School of Optometry and the FRQS Vision Research Network.

Briggs, F., Mangun, G. R., and Usrey, W. M. (2013). Attention enhances synaptic efficacy and the signal-to-noise ratio in neural circuits. Nature 499, 476-480. doi: $10.1038 /$ nature 12276

Bröcher, S., Artola, A., and Singer, W. (1992). Agonists of cholinergic and noradrenergic receptors facilitate synergistically the induction of long-term potentiation in slices of rat visual cortex. Brain Res. 573, 27-36. doi: 10. 1016/0006-8993(92)90110-u

Burkhalter, A. (1989). Intrinsic connections of rat primary visual cortex: laminar organization of axonal projections. J. Comp. Neurol. 279, 171-186. doi: 10. 1002/cne.902790202

Bymaster, F. P., McKinzie, D. L., Felder, C. C., and Wess, J. (2003). Use of M1-M5 muscarinic receptor knockout mice as novel tools to delineate the physiological roles of the muscarinic cholinergic system. Neurochem. Res. 28, 437-442. doi: 10.1023/A:1022844517200

Cardin, J. A., Carlén, M., Meletis, K., Knoblich, U., Zhang, F., Deisseroth, K., et al. (2009). Driving fast-spiking cells induces gamma rhythm and controls sensory responses. Nature 459, 663-667. doi: 10.1038/nature08002

Caulfield, M. P., and Birdsall, N. J. (1998). International union of pharmacology. XVII. Classification of muscarinic acetylcholine receptors. Pharmacol. Rev. 50, 279-290.

Collier, B., and Mitchell, J. F. (1966). The central release of acetylcholine during stimulation of the visual pathway. J. Physiol. 184, 239-254. doi: 10. 1113/jphysiol.1966.sp007913

Consonni, S., Leone, S., Becchetti, A., and Amadeo, A. (2009). Developmental and neurochemical features of cholinergic neurons in the murine cerebral cortex. BMC Neurosci. 10:18. doi: 10.1186/1471-2202-10-18

Crair, M. C., and Malenka, R. C. (1995). A critical period for long-term potentiation at thalamocortical synapses. Nature 375, 325-328. doi: 10 $1038 / 375325 \mathrm{a} 0$

Cynader, M. S., Swindale, N. V., and Matsubara, J. A. (1987). Functional topography in cat area 18. J. Neurosci. 7, 1401-1413. 
DeAngelis, G. C., Ghose, G. M., Ohzawa, I., and Freeman, R. D. (1999). Functional micro-organization of primary visual cortex: receptive field analysis of nearby neurons. J. Neurosci. 19, 4046-4064.

de Marchena, J., Roberts, A. C., Middlebrooks, P. G., Valakh, V., Yashiro, K., Wilfley, L. R., et al. (2008). NMDA receptor antagonists reveal age-dependent differences in the properties of visual cortical plasticity. J. Neurophysiol. 100, 1936-1948. doi: 10.1152/jn.90290.2008

Descarries, L., Gisiger, V., and Steriade, M. (1997). Diffuse transmission by acetylcholine in the CNS. Prog. Neurobiol. 53, 603-625. doi: 10.1016/s03010082(97)00050-6

Disney, A. A., and Aoki, C. (2008). Muscarinic acetylcholine receptors in macaque V1 are most frequently expressed by parvalbumin-immunoreactive neurons. J. Comp. Neurol. 507, 1748-1762. doi: 10.1002/cne.21616

Disney, A. A., Aoki, C., and Hawken, M. J. (2007). Gain modulation by nicotine in macaque v1. Neuron 56, 701-713. doi: 10.1016/j.neuron.2007. 09.034

Disney, A. A., Domakonda, K. V., and Aoki, C. (2006). Differential expression of muscarinic acetylcholine receptors across excitatory and inhibitory cells in visual cortical areas V1 and V2 of the macaque monkey. J. Comp. Neurol. 499, 49-63. doi: 10.1002/cne.21096

Dotigny, F., Ben Amor, A. Y., Burke, M., and Vaucher, E. (2008). Neuromodulatory role of acetylcholine in visually-induced cortical activation: behavioral and neuroanatomical correlates. Neuroscience 154, 1607-1618. doi: 10.1016/j.neuroscience.2008.04.030

Douglas, C. L., Baghdoyan, H. A., and Lydic, R. (2001). M2 muscarinic autoreceptors modulate acetylcholine release in prefrontal cortex of C57BL/6J mouse. J. Pharmacol. Exp. Ther. 299, 960-966.

Dräger, U. C., and Olsen, J. F. (1980). Origins of crossed and uncrossed retinal projections in pigmented and albino mice. J. Comp. Neurol. 191, 383-412. doi: 10.1002/cne.901910306

Dringenberg, H. C., Hamze, B., Wilson, A., Speechley, W., and Kuo, M. C. (2007). Heterosynaptic facilitation of in vivo thalamocortical long-term potentiation in the adult rat visual cortex by acetylcholine. Cereb. Cortex 17, 839-848. doi: 10. 1093/cercor/bhk038

Eggermann, E., and Feldmeyer, D. (2009). Cholinergic filtering in the recurrent excitatory microcircuit of cortical layer 4. Proc. Natl. Acad. Sci. U S A 106, 11753-11758. doi: 10.1073/pnas.0810062106

Elhusseiny, A., and Hamel, E. (2000). Muscarinic-but not nicotinic-acetylcholine receptors mediate a nitric oxide-dependent dilation in brain cortical arterioles: a possible role for the M5 receptor subtype. J. Cereb. Blood Flow Metab. 20, 298-305. doi: 10.1097/00004647-200002000-00011

Fagiolini, M., Pizzorusso, T., Berardi, N., Domenici, L., and Maffei, L. (1994). Functional postnatal development of the rat primary visual cortex and the role of visual experience: dark rearing and monocular deprivation. Vision Res. 34, 709-720. doi: 10.1016/0042-6989(94)90210-0

Flynn, D. D., Ferrari-Dileo, G., Mash, D. C., and Levey, A. I. (1995). Differential regulation of molecular subtypes of muscarinic receptors in Alzheimer's disease. J. Neurochem. 64, 1888-1891. doi: 10.1046/j.1471-4159.1995.640 41888.x

Frenkel, M. Y., Sawtell, N. B., Diogo, A. C., Yoon, B., Neve, R. L., and Bear, M. F. (2006). Instructive effect of visual experience in mouse visual cortex. Neuron 51, 339-349. doi: 10.1016/j.neuron.2006.06.026

Fries, P. (2009). Neuronal gamma-band synchronization as a fundamental process in cortical computation. Annu. Rev. Neurosci. 32, 209-224. doi: 10. 1146/annurev.neuro.051508.135603

Froemke, R. C., Merzenich, M. M., and Schreiner, C. E. (2007). A synaptic memory trace for cortical receptive field plasticity. Nature 450, 425-429. doi: 10 . 1038/nature06289

Gaykema, R. P., Luiten, P. G., Nyakas, C., and Traber, J. (1990). Cortical projection patterns of the medial septum-diagonal band complex. J. Comp. Neurol. 293, 103-124. doi: 10.1002/cne.902930109

Gil, Z., Connors, B. W., and Amitai, Y. (1997). Differential regulation of neocortical synapses by neuromodulators and activity. Neuron 19, 679-686. doi: 10.1016/s0896-6273(00)80380-3

Gilbert, C. D., and Li, W. (2012). Adult visual cortical plasticity. Neuron 75, 250-264. doi: 10.1016/j.neuron.2012.06.030

Goard, M., and Dan, Y. (2009). Basal forebrain activation enhances cortical coding of natural scenes. Nat. Neurosci. 12, 1444-1449. doi: 10.1038/ nn. 2402
Greuel, J. M., Luhmann, H. J., and Singer, W. (1988). Pharmacological induction of use-dependent receptive field modifications in the visual cortex. Science 242, 74-77. doi: 10.1126/science.2902687

Grieve, K. L. (2005). Binocular visual responses in cells of the rat dLGN. J. Physiol. 566, 119-124. doi: 10.1113/jphysiol.2005.090878

Grinvald, A., Lieke, E., Frostig, R. D., Gilbert, C. D., and Wiesel, T. N. (1986). Functional architecture of cortex revealed by optical imaging of intrinsic signals. Nature 324, 361-364. doi: 10.1038/324361a0

Groleau, M., Nguyen, H. N., Vanni, M. P., Huppé-Gourgues, F., Casanova, C., and Vaucher, E. (2014). Impaired functional organization in the visual cortex of muscarinic receptor knock-out mice. Neuroimage 98, 233-242. doi: 10.1016/j. neuroimage.2014.05.016

$\mathrm{Gu}, \mathrm{Q}$. (2003). Contribution of acetylcholine to visual cortex plasticity. Neurobiol. Learn. Mem. 80, 291-301. doi: 10.1016/s1074-7427(03)00073-x

$\mathrm{Gu}$, Q., and Singer, W. (1993). Effects of intracortical infusion of anticholinergic drugs on neuronal plasticity in kitten striate cortex. Eur. J. Neurosci. 5, 475-485. doi: 10.1111/j.1460-9568.1993.tb00514.x

Gulledge, A. T., Bucci, D. J., Zhang, S. S., Matsui, M., and Yeh, H. H. (2009). M1 receptors mediate cholinergic modulation of excitability in neocortical pyramidal neurons. J. Neurosci. 29, 9888-9902. doi: 10.1523/jneurosci.1366-09. 2009

Hashimoto, T., Shu, H., and Kuriyama, K. (1994). Muscarinic M1 receptor mediated inhibition of GABA release from rat cerebral cortex. Neurochem. Int. 24, 389-394. doi: 10.1016/0197-0186(94)90117-1

Headley, D. B., and Weinberger, N. M. (2011). Gamma-band activation predicts both associative memory and cortical plasticity. J. Neurosci. 31, 12748-12758. doi: 10.1523/jneurosci.2528-11.2011

Hensch, T. K., and Fagiolini, M. (2005). Excitatory-inhibitory balance and critical period plasticity in developing visual cortex. Prog. Brain Res. 147, 115-124. doi: 10.1016/s0079-6123(04)47009-5

Herrero, J. L., Roberts, M. J., Delicato, L. S., Gieselmann, M. A., Dayan, P., and Thiele, A. (2008). Acetylcholine contributes through muscarinic receptors to attentional modulation in V1. Nature 454, 1110-1114. doi: 10 1038/nature07141

Hofer, S. B., Mrsic-Flogel, T. D., Bonhoeffer, T., and Hübener, M. (2009). Experience leaves a lasting structural trace in cortical circuits. Nature 457, 313-317. doi: 10.1038/nature07487

Jehee, J. F., Ling, S., Swisher, J. D., Van Bergen, R. S., and Tong, F. (2012). Perceptual learning selectively refines orientation representations in early visual cortex. J. Neurosci. 32, 16747-16753a. doi: 10.1523/jneurosci.6112-11. 2012

Jositsch, G., Papadakis, T., Haberberger, R. V., Wolff, M., Wess, J., and Kummer, W. (2009). Suitability of muscarinic acetylcholine receptor antibodies for immunohistochemistry evaluated on tissue sections of receptor genedeficient mice. Naunyn Schmiedebergs Arch. Pharmacol. 379, 389-395. doi: 10. 1007/s00210-008-0365-9

Kang, J. I., Huppé-Gourgues, F., and Vaucher, E. (2014). Boosting visual cortex function and plasticity with acetylcholine to enhance visual perception. Front. Syst. Neurosci. 8:172. doi: 10.3389/fnsys.2014.00172

Kang, J. I., and Vaucher, E. (2009). Cholinergic pairing with visual activation results in long-term enhancement of visual evoked potentials. PLoS One 4:e5995. doi: 10.1371/journal.pone.0005995

Kapadia, M. K., Westheimer, G., and Gilbert, C. D. (2000). Spatial distribution of contextual interactions in primary visual cortex and in visual perception. J. Neurophysiol. 84, 2048-2062.

Kimura, F., and Baughman, R. W. (1997). Distinct muscarinic receptor subtypes suppress excitatory and inhibitory synaptic responses in cortical neurons. $J$. Neurophysiol. 77, 709-716.

Kimura, F., Fukuda, M., and Tsumoto, T. (1999). Acetylcholine suppresses the spread of excitation in the visual cortex revealed by optical recording: possible differential effect depending on the source of input. Eur. J. Neurosci. 11, 3597-3609. doi: 10.1046/j.1460-9568.1999. 00779.x

Kirkwood, A., Lee, H. K., and Bear, M. F. (1995). Co-regulation of long-term potentiation and experience-dependent synaptic plasticity in visual cortex by age and experience. Nature 375, 328-331. doi: 10.1038/375328a0

Kirkwood, A., Rozas, C., Kirkwood, J., Perez, F., and Bear, M. F. (1999). Modulation of long-term synaptic depression in visual cortex by acetylcholine and norepinephrine. J. Neurosci. 19, 1599-1609. 
Klinkenberg, I., and Blokland, A. (2010). The validity of scopolamine as a pharmacological model for cognitive impairment: a review of animal behavioral studies. Neurosci. Biobehav. Rev. 34, 1307-1350. doi: 10.1016/j. neubiorev.2010.04.001

Krnjević, K. (2004). Synaptic mechanisms modulated by acetylcholine in cerebral cortex. Prog. Brain Res. 145, 81-93. doi: 10.1016/s0079-6123(03)45005-x

Kuczewski, N., Aztiria, E., Leanza, G., and Domenici, L. (2005). Selective cholinergic immunolesioning affects synaptic plasticity in developing visual cortex. Eur. J. Neurosci. 21, 1807-1814. doi: 10.1111/j.1460-9568.2005. 04014.x

Laplante, F., Morin, Y., Quirion, R., and Vaucher, E. (2005). Acetylcholine release is elicited in the visual cortex, but not in the prefrontal cortex, by patterned visual stimulation: a dual in vivo microdialysis study with functional correlates in the rat brain. Neuroscience 132, 501-510. doi: 10.1016/j.neuroscience.2004. 11.059

LeVay, S., Stryker, M. P., and Shatz, C. J. (1978). Ocular dominance columns and their development in layer IV of the cat's visual cortex: a quantitative study. J. Comp. Neurol. 179, 223-244. doi: 10.1002/cne.901790113

Levey, A. I., Edmunds, S. M., Heilman, C. J., Desmond, T. J., and Frey, K. A. (1994). Localization of muscarinic $\mathrm{m} 3$ receptor protein and M3 receptor binding in rat brain. Neuroscience 63, 207-221. doi: 10.1016/0306-4522(94) 90017-5

Levey, A. I., Kitt, C. A., Simonds, W. F., Price, D. L., and Brann, M. R. (1991). Identification and localization of muscarinic acetylcholine receptor proteins in brain with subtype-specific antibodies. J. Neurosci. 11, 3218-3226.

Levitt, J. B., and Lund, J. S. (1997). Contrast dependence of contextual effects in primate visual cortex. Nature 387, 73-76. doi: 10.1038/387073a0

Levy, R. B., Reyes, A. D., and Aoki, C. (2006). Nicotinic and muscarinic reduction of unitary excitatory postsynaptic potentials in sensory cortex; dual intracellular recording in vitro. J. Neurophysiol. 95, 2155-2166. doi: 10.1152/jn. 00603.2005

Lewandowski, M. H., Müller, C. M., and Singer, W. (1993). Reticular facilitation of cat visual cortical responses is mediated by nicotinic and muscarinic cholinergic mechanisms. Exp. Brain Res. 96, 1-7. doi: 10.1007/bf00 230433

Lucas-Meunier, E., Fossier, P., Baux, G., and Amar, M. (2003). Cholinergic modulation of the cortical neuronal network. Pflugers Arch. 446, 17-29.

Mainardi, M., Landi, S., Berardi, N., Maffei, L., and Pizzorusso, T. (2009). Reduced responsiveness to long-term monocular deprivation of parvalbumin neurons assessed by c-Fos staining in rat visual cortex. PLoS One 4:e4342. doi: 10. 1371/journal.pone. 0004342

Majewska, A., and Sur, M. (2003). Motility of dendritic spines in visual cortex in vivo: changes during the critical period and effects of visual deprivation. Proc. Natl. Acad. Sci. U S A 100, 16024-16029. doi: 10.1073/pnas.2636949100

Mash, D. C., and Potter, L. T. (1986). Autoradiographic localization of M1 and M2 muscarine receptors in the rat brain. Neuroscience 19, 551-564. doi: 10. 1016/0306-4522(86)90280-0

Matthews, N., Liu, Z., Geesaman, B. J., and Qian, N. (1999). Perceptual learning on orientation and direction discrimination. Vision Res. 39, 3692-3701. doi: 10. 1016/s0042-6989(99)00069-3

McCoy, P. A., and McMahon, L. L. (2010). Sympathetic sprouting in visual cortex stimulated by cholinergic denervation rescues expression of two forms of longterm depression at layer 2/3 synapses. Neuroscience 168, 591-604. doi: 10. 1016/j.neuroscience.2010.04.027

Mechawar, N., and Descarries, L. (2001). The cholinergic innervation develops early and rapidly in the rat cerebral cortex: a quantitative immunocytochemical study. Neuroscience 108, 555-567. doi: 10.1016/s0306-4522(01)00389-x

Mrzljak, L., Levey, A. I., and Goldman-Rakic, P. S. (1993). Association of $\mathrm{m} 1$ and $\mathrm{m} 2$ muscarinic receptor proteins with asymmetric synapses in the primate cerebral cortex: morphological evidence for cholinergic modulation of excitatory neurotransmission. Proc. Natl. Acad. Sci. U S A 90, 5194-5198. doi: $10.1073 /$ pnas.90.11.5194

Murphy, P. C., and Sillito, A. M. (1991). Cholinergic enhancement of direction selectivity in the visual cortex of the cat. Neuroscience 40, 13-20. doi: 10 . 1016/0306-4522(91)90170-s

Oldford, E., and Castro-Alamancos, M. A. (2003). Input-specific effects of acetylcholine on sensory and intracortical evoked responses in the "barrel cortex" in vivo. Neuroscience 117, 769-778. doi: 10.1016/s0306-4522(02) 00663-2
Origlia, N., Kuczewski, N., Aztiria, E., Gautam, D., Wess, J., and Domenici, L. (2006). Muscarinic acetylcholine receptor knockout mice show distinct synaptic plasticity impairments in the visual cortex. J. Physiol. 577, 829-840. doi: 10.1113/jphysiol.2006.117119

Paik, S. B., and Glaser, D. A. (2010). Synaptic plasticity controls sensory responses through frequency-dependent gamma oscillation resonance. PLoS Comput. Biol. 6:e1000927. doi: 10.1371/journal.pcbi.1000927

Pinto, L., Goard, M. J., Estandian, D., Xu, M., Kwan, A. C., Lee, S. H., et al. (2013). Fast modulation of visual perception by basal forebrain cholinergic neurons. Nat. Neurosci. 16, 1857-1863. doi: 10.1038/nn.3552

Prusky, G. T., Shaw, C., and Cynader, M. S. (1987). Nicotine receptors are located on lateral geniculate nucleus terminals in cat visual cortex. Brain Res. 412, 131-138. doi: 10.1016/0006-8993(87)91447-8

Quinlan, E. M., Lebel, D., Brosh, I., and Barkai, E. (2004). A molecular mechanism for stabilization of learning-induced synaptic modifications. Neuron 41, 185-192. doi: 10.1016/s0896-6273(03)00874-2

Ramalingam, N., McManus, J. N., Li, W., and Gilbert, C. D. (2013). Top-down modulation of lateral interactions in visual cortex. J. Neurosci. 33, 1773-1789. doi: 10.1523/jneurosci.3825-12.2013

Roberts, M. J., Zinke, W., Guo, K., Robertson, R., McDonald, J. S., and Thiele, A. (2005). Acetylcholine dynamically controls spatial integration in marmoset primary visual cortex. J. Neurophysiol. 93, 2062-2072. doi: 10.1152/jn.00911. 2004

Rodriguez, R., Kallenbach, U., Singer, W., and Munk, M. H. (2004). Shortand long-term effects of cholinergic modulation on gamma oscillations and response synchronization in the visual cortex. J. Neurosci. 24, 10369-10378. doi: 10.1523/jneurosci.1839-04.2004

Rodriguez, R., Kallenbach, U., Singer, W., and Munk, M. H. (2010). Stabilization of visual responses through cholinergic activation. Neuroscience 165, 944-954. doi: 10.1016/j.neuroscience.2009.10.059

Rokem, A., and Silver, M. A. (2010). Cholinergic enhancement augments magnitude and specificity of visual perceptual learning in healthy humans. Curr. Biol. 20, 1723-1728. doi: 10.1016/j.cub.2010.08.027

Rouse, S. T., Marino, M. J., Potter, L. T., Conn, P. J., and Levey, A. I. (1999). Muscarinic receptor subtypes involved in hippocampal circuits. Life Sci. 64, 501-509. doi: 10.1016/s0024-3205(98)00594-3

Sale, A., Berardi, N., Spolidoro, M., Baroncelli, L., and Maffei, L. (2010). GABAergic inhibition in visual cortical plasticity. Front. Cell. Neurosci. 4:10. doi: 10.3389 /fncel.2010.00010

Salgado, H., Bellay, T., Nichols, J. A., Bose, M., Martinolich, L., Perrotti, L., et al. (2007). Muscarinic M2 and M1 receptors reduce GABA release by $\mathrm{Ca} 2+$ channel modulation through activation of PI3K/Ca2+ -independent and PLC/Ca2+ -dependent PKC. J. Neurophysiol. 98, 952-965. doi: 10.1152/jn. 00060.2007

Sarter, M., Hasselmo, M. E., Bruno, J. P., and Givens, B. (2005). Unraveling the attentional functions of cortical cholinergic inputs: interactions between signaldriven and cognitive modulation of signal detection. Brain Res. Brain Res. Rev. 48, 98-111. doi: 10.1016/j.brainresrev.2004.08.006

Sarter, M., and Parikh, V. (2005). Choline transporters, cholinergic transmission and cognition. Nat. Rev. Neurosci. 6, 48-56. doi: 10.1038/nrn1588

Shmuel, A., and Grinvald, A. (1996). Functional organization for direction of motion and its relationship to orientation maps in cat area 18. J. Neurosci. 16, 6945-6964.

Siciliano, R., Fontanesi, G., Casamenti, F., Berardi, N., Bagnoli, P., and Domenici, L. (1997). Postnatal development of functional properties of visual cortical cells in rats with excitotoxic lesions of basal forebrain cholinergic neurons. Vis. Neurosci. 14, 111-123. doi: 10.1017/s0952523800008816

Silver, M. A., Shenhav, A., and D'esposito, M. (2008). Cholinergic enhancement reduces spatial spread of visual responses in human early visual cortex. Neuron 60, 904-914. doi: 10.1016/j.neuron.2008.09.038

Sohal, V. S., Zhang, F., Yizhar, O., and Deisseroth, K. (2009). Parvalbumin neurons and gamma rhythms enhance cortical circuit performance. Nature 459, 698-702. doi: 10.1038/nature07991

Soma, S., Shimegi, S., Osaki, H., and Sato, H. (2012). Cholinergic modulation of response gain in the primary visual cortex of the macaque. J. Neurophysiol. 107, 283-291. doi: 10.1152/jn.00330.2011

Soma, S., Shimegi, S., Suematsu, N., and Sato, H. (2013a). Cholinergic modulation of response gain in the rat primary visual cortex. Sci. Rep. 3:1138. doi: 10 . 1038/srep01138 
Soma, S., Shimegi, S., Suematsu, N., Tamura, H., and Sato, H. (2013b). Modulation-specific and laminar-dependent effects of acetylcholine on visual responses in the rat primary visual cortex. PLoS One 8:e68430. doi: 10. 1371/journal.pone.0068430

Soma, S., Suematsu, N., and Shimegi, S. (2013c). Cholinesterase inhibitor, donepezil, improves visual contrast detectability in freely behaving rats. Behav. Brain Res. 256, 362-367. doi: 10.1016/j.bbr.2013.08.022

Thiel, C. M. (2007). Pharmacological modulation of learning-induced plasticity in human auditory cortex. Restor. Neurol. Neurosci. 25, 435-443.

Thiel, C. M., and Fink, G. R. (2008). Effects of the cholinergic agonist nicotine on reorienting of visual spatial attention and top-down attentional control. Neuroscience 152, 381-390. doi: 10.1016/j.neuroscience.2007.10.061

Thiele, A. (2013). Muscarinic signaling in the brain. Annu. Rev. Neurosci. 36, 271-294. doi: 10.1146/annurev-neuro-062012-170433

Turrini, P., Casu, M. A., Wong, T. P., De Koninck, Y., Ribeiro-Da-Silva, A., and Cuello, A. C. (2001). Cholinergic nerve terminals establish classical synapses in the rat cerebral cortex: synaptic pattern and age-related atrophy. Neuroscience 105, 277-285. doi: 10.1016/s0306-4522(01)00172-5

Umbriaco, D., Watkins, K. C., Descarries, L., Cozzari, C., and Hartman, B. K. (1994). Ultrastructural and morphometric features of the acetylcholine innervation in adult rat parietal cortex: an electron microscopic study in serial sections. J. Comp. Neurol. 348, 351-373. doi: 10.1002/cne.903480304

Van Hooser, S. D. (2007). Similarity and diversity in visual cortex: is there a unifying theory of cortical computation? Neuroscientist 13, 639-656. doi: 10. $1177 / 1073858407306597$

Vaucher, E., Reymond, I., Najaffe, R., Kar, S., Quirion, R., Miller, M. M., et al. (2002). Estrogen effects on object memory and cholinergic receptors in young and old female mice. Neurobiol. Aging 23, 87-95. doi: 10.1016/s01974580(01)00250-0

Volpicelli, L. A., and Levey, A. I. (2004). Muscarinic acetylcholine receptor subtypes in cerebral cortex and hippocampus. Prog. Brain Res. 145, 59-66. doi: 10.1016/s0079-6123(03)45003-6
Wess, J. (2003). Novel insights into muscarinic acetylcholine receptor function using gene targeting technology. Trends Pharmacol. Sci. 24, 414-420. doi: 10. 1016/s0165-6147(03)00195-0

Yamahachi, H., Marik, S. A., McManus, J. N., Denk, W., and Gilbert, C. D. (2009). Rapid axonal sprouting and pruning accompany functional reorganization in primary visual cortex. Neuron 64, 719-729. doi: 10.1016/j.neuron.2009. 11.026

Zhang, W., Basile, A. S., Gomeza, J., Volpicelli, L. A., Levey, A. I., and Wess, J. (2002). Characterization of central inhibitory muscarinic autoreceptors by the use of muscarinic acetylcholine receptor knock-out mice. J. Neurosci. 22, 1709-1717.

Zilles, K., Schröder, H., Schröder, U., Horvath, E., Werner, L., Luiten, P. G., et al. (1989). Distribution of cholinergic receptors in the rat and human neocortex. EXS 57, 212-228. doi: 10.1007/978-3-03489138-7_22

Zinke, W., Roberts, M. J., Guo, K., McDonald, J. S., Robertson, R., and Thiele, A. (2006). Cholinergic modulation of response properties and orientation tuning of neurons in primary visual cortex of anaesthetized marmoset monkeys. Eur. J. Neurosci. 24, 314-328. doi: 10.1111/j.1460-9568.2006. 04882.x

Conflict of Interest Statement: The authors declare that the research was conducted in the absence of any commercial or financial relationships that could be construed as a potential conflict of interest.

Copyright (C) 2015 Groleau, Kang, Huppé-Gourgues and Vaucher. This is an openaccess article distributed under the terms of the Creative Commons Attribution License (CC BY). The use, distribution and reproduction in other forums is permitted, provided the original author(s) or licensor are credited and that the original publication in this journal is cited, in accordance with accepted academic practice. No use, distribution or reproduction is permitted which does not comply with these terms. 